\title{
Reversal of left-sided colostomy utilizing single-port laparoscopy a multicenter European audit and overview of the literature
}

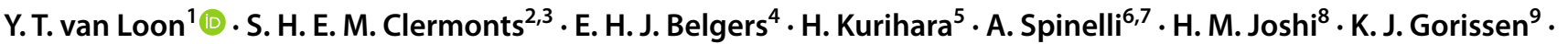 \\ D. D. E. Zimmerman ${ }^{1}$
}

Received: 25 January 2021 / Accepted: 16 July 2021 / Published online: 26 July 2021

(c) The Author(s) 2021

\begin{abstract}
Background Stoma reversal surgery can result in considerable morbidity and even mortality. Feasibility of utilizing singleport laparoscopy through the stoma fenestration have been shown before. Aim of the present observational study is to evaluate multicenter experiences of single-port reversal of left-sided colostomy (SPRLC) throughout Europe and to provide an overview of available literature on this topic.

Methods All patients undergoing SPRLC in four different teaching hospitals throughout Europe are included. Primary outcome was 30-day postoperative complication rate. Secondary outcomes were postoperative length of stay (LOS), single-port success rate and conversion rates. Appraisal of the available literature in PubMed was performed.

Results Of 156 SPRLC procedures, $98.7 \%$ of them were technically successful and $71.8 \%$ were without postoperative complications. No postoperative mortality was encountered. Superficial site infection occurred in $14.7 \%$, anastomotic leakage in 3.9\% and major complications in 8.3\%. Median LOS was 4.0 days (1-69), single-port success rate was $64.7 \%, 12.8 \%$ and $21.2 \%$ (33/154) were converted to an open and multiport laparoscopic procedure, respectively. Literature shows equally favorable results in 131 patients divided over 5 cohorts with morbidity ranging from 0 to $30.4 \%$ and mortality from 0 to $2.2 \%$ and median LOS of $4-8$ days.

Conclusion This study confirms the safety, feasibility and favorable results of the use of single-port approach in the reversal of left-sided colostomy in different centers in Europe with laparoscopic experienced colorectal surgeons. The available literature on this topic support and show equally favorable results using single-port laparoscopy for left-sided colostomy reversal surgery.
\end{abstract}

Keywords Hartmann's procedure $\cdot$ Single-port laparoscopy $\cdot$ Stoma reversal $\cdot$ Hartmann reversal $\cdot$ Single-incision

A part of the results of this manuscript was presented as a poster presentation during the scientific and annual meeting of the European Society of Coloproctology 25-27 September 2019, Vienna, Austria.

Y. T. van Loon

tinavanloon@gmail.com

1 Department of Surgery, Elisabeth-TweeSteden Hospital, Hilvarenbeekseweg 60, 5022GC Tilburg, The Netherlands

2 Department of Surgery, Maastricht University Medical Center, Maastricht, The Netherlands

3 Department of Surgery, Zuyderland Hospital, Heerlen and Sittard, The Netherlands

4 Department of Colorectal Surgery, Humanitas University, Milan, Italy

5 Department of Emergency Surgery and Trauma Unit, Humanitas Clinical and Research Center, IRCCS, Rozzano, Milan, Italy
Stomas are not only used in emergency colorectal surgery for benign disorders such as diverticulitis after a Hartmann's

6 Department of Colon and Rectal Surgery, Humanitas Clinical and Research Center IRCCS, Rozzano, Milan, Italy

7 Department of Biomedical Sciences, Humanitas University, Pieve Emanuele, Rozzano, Milan, Italy

8 Department of Colorectal Surgery, Addenbrooke's Hospital, Cambridge University Hospitals NHS Foundation Trust, Cambridge, UK

9 Department of Emergency and Colorectal Surgery, Oxford University Hospitals NHS Foundation Trust, Oxford, UK 
Procedure (HP) [1-3]; they are also widely accepted and propagated in colorectal cancer surgery. Up to $35 \%$ of the Dutch elderly patients still receive an ostomy after colorectal cancer surgery and patients undergoing emergency colorectal surgery because of left-sided colon malignancy still suffer from significantly higher odds of a colostomy [4-6]

Pursuing stoma reversal surgery is not without risks; anastomotic leakage rates range from 4 to $16 \%$, perioperative mortality and morbidity rates are reported as high as $14 \%$ and $40 \%$, respectively [7-10]. These are the main reasons why many surgeons are reluctant to perform stoma reversal surgery; in up to $40 \%$ of the patients, stoma reversal will never be performed [8-10].

In 1993 laparoscopic reversal of HP was introduced in an effort to reduce morbidity and mortality [11]. It was shown to have considerable advantages over classic open reversal of HP [11, 12]. Further evolution of minimal invasive abdominal surgery introduced the use of single-port laparoscopy, this approach has also been used for stoma reversal surgery, first described by Smith and Bettinger [13]. The necessity of difficult trocar placement and laborious midline adhesiolysis are obvious advantages of the single-port approach over the conventional laparoscopic approach $[14,15]$. Previous studies show that single-port reversal of a left-sided colostomy (SPRLC) is feasible, safe and also results in significant shorter length of stay and reduction of postoperative complications as superficial site infections compared to classic open stoma reversal surgery [3,15]. Adoption of this approach has led to an increasing body of literature on SPRLC since its introduction in 2011.

Aim of the present study was to evaluate the results of single-port reversal of left-sided colostomy (SPRLC) in a multicenter setting across different countries in Europe and to give a comprehensive overview of the literature on the use of the single-port (SP) approach in the reversal of a left-sided colostomy. We postulate that SPRLC is feasible and safe with a shorter hospital stay and less postoperative morbidity compared to an open approach.

\section{Materials and methods}

This is a retrospective observational study, all patients undergoing SPRLC in four different teaching hospitals throughout Europe were included in present analysis. The four different hospitals are Churchill Hospital in the United Kingdom $(\mathrm{CH})$, Humanitas Research Hospital (HRH) in Italy, Elisabeth-TweeSteden Hospital (ETH) and Zuyderland Medical Center (ZMC) both in the Netherlands. Approval of the institutional review board or ethics committee was not required because of the retrospective and observational character of this study. This report was prepared in concordance with the STROBE guidelines [16].
Patient characteristics (sex, age, length and weight), index surgery characteristics (reason for surgery and postoperative complications), surgical details (time interval between index surgery and SPRLC, duration of SPRLC, conversion to multiport laparoscopy or laparotomy, colostomy site closure methods) and postoperative outcomes (length of stay, complications, readmissions) were collected in electronic case report forms by local investigators using the electronic patient records. All procedures were performed or supervised by experienced colorectal surgeons or consultants with extensive skills in laparoscopy and minimally invasive surgery. Patients undergoing stoma reversal of a loop or right-sided colostomy or ileostomy or via open procedure were excluded. This study included cases previously published by authors from our current collaborative group from Clermonts and van Loon $(\mathrm{ETH})$ and Joshi $(\mathrm{CH})[3$, 15, 17]. In $\mathrm{CH}$ and ETH all consecutive patients eligible for HP reversal were included, without additional patient selection or exclusion in the enrollment period from 2010-2019 and 2012-2020, respectively. Patients included from HRH (2008-2019) and ZMC (2015-2018) were selected by their operating surgeon by the surgeon's preference, in these hospitals all procedures were performed by one (supervising) surgeon. In HRH patients included in this study comprised almost half of all the patients who underwent stoma reversal surgery. Single-port laparoscopy is the preferred approach of choice in $\mathrm{CH}$ and $\mathrm{ETH}$ when performing stoma reversal surgery for left-sided colostomies. SPRLC became the preferred approach of choice towards the second half of the study period in HRH. The preferred approach for stoma reversal surgery in ZMC is surgeon dependent.

\section{Surgical technique}

All patients were placed in modified lithotomy position and given metronidazole $500 \mathrm{mg}$ and cefuroxime $1500 \mathrm{mg}$ intravenously. The operative procedure of the SPRLC has been described in detail previously [3, 13-15, 17-19]. In short, the colostomy was mobilized down to the fascia and the anvil for a circular stapler was placed in the descending colon before returning it to the abdominal cavity through the original colostomy site. Pneumoperitoneum was established after placement of a single-port device or surgical gloveport. Where necessary, the splenic flexure or transverse colon was mobilized and adhesiolysis was performed under direct vision. Continuity was restored after adhesiolysis and proper visualization of the rectal stump with the use of a circular stapler. An air leak test was performed before port removal. Fascia and skin at colostomy site were closed as deemed appropriate. See Table 1 for a detailed description of the materials and techniques used during SPRLC.

All patients were treated within an established Enhanced Recovery After Surgery (ERAS) protocol [20]. 
Table 1 Overview of materials used during single-port reversal of left-sided colostomy

\begin{tabular}{|c|c|c|c|c|}
\hline Center, Country & Type of stapler & Type of single-port access & Closure of fascia & Closure of skin \\
\hline Humanitas, Italy & EEA28 ${ }^{\mathrm{TM}}$ EEA31 $1^{\mathrm{TM}}$ & GelPOINTTM & Interrupted stitches, Vicryl & Sutures and staples \\
\hline Churchill, United Kingdom & $\mathrm{CDH} 29 \mathrm{~A}$ & Surgical glove-port & Running suture, PDS & $\begin{array}{l}\text { Skin glue, staples and sutures, } \\
\text { Monocryl }\end{array}$ \\
\hline Zuyderland, Netherlands & $\mathrm{CDH} 29 \mathrm{~A}$ & $\begin{array}{l}\text { OCTO }{ }^{\mathrm{TM}} \text { Port, surgical glove- } \\
\text { port }\end{array}$ & Running suture, PDS & $\begin{array}{l}\text { Intracutaneous purse-string } \\
\text { suture, Vicryl }\end{array}$ \\
\hline $\begin{array}{l}\text { Elisabeth-TweeSteden, Neth- } \\
\text { erlands }\end{array}$ & CDH29A, EEA ${ }^{\mathrm{TM}, \mathrm{a}}$ & GelPOINT $^{\mathrm{TM}}$ & Running suture, PDS & $\begin{array}{l}\text { Intracutaneous, purse-string } \\
\text { sutures, Monocryl }\end{array}$ \\
\hline
\end{tabular}

EEA $^{\text {TM }}$ circular stapler, Medtronic CDH29A, Ethicon J\&J

GelPOINTTM, Applied Medical

OCTO $^{\mathrm{TM}}$ Port, Dalim SurgNet, Frankenman

Vicryl: polyglactin suture, Ethicon J\&J; PDS: polydioxanone suture, Ethicon J\&J; Monocryl: polyglactin suture, Ethicon J\&J

${ }^{\mathrm{a}}$ This hospital switched to the EEA ${ }^{\mathrm{TM}}$ stapler from 2017

Important components of the ERAS protocol applied similarly in all centers are antimicrobial prophylaxis with skin preparation, perioperative near-zero fluid balance, no use of pelvic, peritoneal or nasogastric drains or tubes, multimodal analgesia without use of NSAIDs, early postoperative mobilization and oral diet. Patients were discharged from the hospital when they were able to tolerate normal food, pass stool, were able to mobilize at a level that was similar to preoperative levels of mobilization and had adequate control of pain with use of oral analgesia. Minimum follow up period consisted of 30 days postoperatively.

\section{Outcomes}

Primary outcome was 30-days postoperative complication defined as infections (surgical site, intra-abdominal abscess), urogenital complications (urinary tract infection, urine retention), ileus or gastroparesis, pulmonary complications (pneumonia, exacerbation) and blood-related complications (rectal blood loss, thrombosis or hematoma in wound or anastomosis) was classified using the Clavien-Dindo score. Clavien-Dindo grade 3 or higher were considered major complications in this analysis.

Secondary outcomes were postoperative length of stay (LOS), technical and single-port success rate, other surgical details of the procedure such as duration, conversion to multiport laparoscopy or open and overall success rate of SPRLC. Technical success rate is defined as successful stoma reversal with creation of an anastomosis. Singleport success rate is defined as successful stoma reversal solely using the single-port technique without placement of additional laparoscopic trocars or conversion to open surgery. Placement of additional trocars besides the OCTO $^{\text {Tм }}$ Port, GelPOINT Path Access Platform or single-site glove-port is considered conversion to multiport laparoscopy.

\section{Statistical analysis}

Descriptive statistics were expressed as median and range (minimum, maximum) for continuous variables. The Pearson $\chi^{2}$ test or the Fisher exact tests, if appropriate, were used for categorical variables. Mann-Whitney $U$ and Kruskal-Wallis test was used for continuous variables. Statistical analysis was performed using the SPSS software package version 26 (SPSS, Chicago, IL). All $p$ values $<0.05$ were considered statistically significant.

\section{Appraisal of the literature}

A literature search for relevant literature from 2011 (the introduction of single-port reversal of HP) on was performed using PubMed. Articles were screened using title and abstract. When multiple articles from a single study group with matching authors was found, only most recent was used in an effort to reduce duplication bias. Previous published articles on this topic from our current collaborative group of authors were excluded.

\section{Results}

A total of 156 patients were included from four different surgical departments throughout Europe: 30 patients from $\mathrm{CH}, 13$ patients from $\mathrm{HRH}$ in Italy, 9 patients from $\mathrm{ZMC}$ and 104 patients from ETH.

The majority of the patients are male ( $\mathrm{m}: \mathrm{f}=99: 57)$, ASA 2 or 3 (40.4\% and $34.6 \%$, respectively) with a median age of 61.0 years (range 17.7-92.6). Majority of the index surgeries were via conventional open approach $(64.7 \%)$, most common indications for index surgery were diverticulitis (58\%) or colorectal cancer (23.7\%). 
The median time between the index surgery and SPRLC is approximately 9 months (284 days). An overview of patient specific characteristics at baseline can be found in Table 2.

\section{Postoperative results}

No 30-day postoperative mortality was encountered in the present series. Majority $(112 / 156,71.8 \%)$ of the patients encountered no 30-day postoperative complications whatsoever, $28.2 \%$ of the patients encountered at least one postoperative complication. Major complications were encountered

Table 2 Patient characteristics at baseline per center

\begin{tabular}{|c|c|c|c|c|c|c|c|c|c|}
\hline \multirow{2}{*}{$\begin{array}{l}\text { Center, country } \\
\text { Humanitas, Italy }\end{array}$} & \multirow{2}{*}{$\begin{array}{l}\text { Number } \\
13\end{array}$} & \multirow{2}{*}{$\begin{array}{l}\text { Sex M:F } \\
9: 4\end{array}$} & \multirow{2}{*}{$\begin{array}{l}\begin{array}{l}\text { Median age } \\
\text { (range) }\end{array} \\
64.5(21.2-92.6)\end{array}$} & \multirow{2}{*}{$\begin{array}{l}\begin{array}{l}\text { Median BMI } \\
\text { (range) }\end{array} \\
24.4(18.2-34.7)\end{array}$} & \multicolumn{2}{|c|}{ ASA $n(\%)$} & \multicolumn{2}{|c|}{ Reason for stoma n (\%) } & \multirow{2}{*}{$\begin{array}{l}\text { Primary open } \\
\text { approach } n(\%) \\
10(76.9)\end{array}$} \\
\hline & & & & & 1 & $1(7.7)$ & Diverticulitis & $4(30.8)$ & \\
\hline & & & & & 2 & $9(69.2)$ & Malignancy & $4(30.8)$ & \\
\hline & & & & & 3 & $3(23.1)$ & $\begin{array}{l}\text { Perforation or } \\
\text { trauma }\end{array}$ & $3(23.1)$ & \\
\hline & & & & & 4 & - & $\begin{array}{l}\text { Inflammatory } \\
\text { Bowel Disease }\end{array}$ & $1(1.8)$ & \\
\hline & & & & & & & Clostridium & $1(1.8)$ & \\
\hline \multirow{7}{*}{$\begin{array}{l}\text { Churchill, United } \\
\text { Kingdom }\end{array}$} & 30 & $16: 14$ & $60.0(17.7-80.1)$ & $26.0(19.0-45.2)$ & & & Diverticulitis & $17(56.7)$ & $25(83.3)$ \\
\hline & & & & & 1 & $1(3.3)$ & Malignancy & $5(16.7)$ & \\
\hline & & & & & 2 & $7(23.3)$ & $\begin{array}{l}\text { Perforation or } \\
\text { trauma }\end{array}$ & $3(10.0)$ & \\
\hline & & & & & 3 & $18(60.0)$ & $\begin{array}{l}\text { Anastomotic } \\
\text { leakage }\end{array}$ & $2(6.7)$ & \\
\hline & & & & & 4 & $4(13.3)$ & Ischemia & $1(3.3)$ & \\
\hline & & & & & & & Volvulus & $1(3.3)$ & \\
\hline & & & & & & & Stoma retraction & $1(3.3)$ & \\
\hline \multirow{5}{*}{$\begin{array}{l}\text { Zuyderland, The } \\
\text { Netherlands }\end{array}$} & 9 & $6: 3$ & $56.1(37.5-67.2)$ & $25.6(21.1-33.6)$ & 1 & $2(22.2)$ & Diverticulitis & $4(44.4)$ & $6(66.7)$ \\
\hline & & & & & 2 & $4(44.4)$ & Malignancy & $2(22.2)$ & \\
\hline & & & & & 3 & $3(33.3)$ & Volvulus & $1(11.1)$ & \\
\hline & & & & & 4 & - & Ischemia & $1(11.1)$ & \\
\hline & & & & & & & $\begin{array}{l}\text { Perforation or } \\
\text { trauma }\end{array}$ & $1(11.1)$ & \\
\hline \multirow{7}{*}{$\begin{array}{l}\text { Elisabeth-Twe- } \\
\text { eSteden, The } \\
\text { Netherlands }\end{array}$} & 104 & 68: 36 & $61.0(25.5-85.0)$ & $26.4(18.3-61.1)$ & & & Diverticulitis & $66(63.5)$ & $60(57.7)$ \\
\hline & & & & & 1 & $25(24.0)$ & Malignancy & $26(25.0)$ & \\
\hline & & & & & 2 & $43(41.3)$ & $\begin{array}{l}\text { Perforation or } \\
\text { trauma }\end{array}$ & $6(5.7)$ & \\
\hline & & & & & 3 & $30(28.8)$ & Ischemia & $2(1.9)$ & \\
\hline & & & & & 4 & $6(5.8)$ & Volvulus & $2(1.9)$ & \\
\hline & & & & & & & $\begin{array}{l}\text { Inflammatory } \\
\text { Bowel Disease }\end{array}$ & $1(1.0)$ & \\
\hline & & & & & & & Perianal abscesses & $1(1.0)$ & \\
\hline \multirow[t]{8}{*}{ Cumulative } & 156 & 99: 57 & $61.0(17.7-92.6)$ & $26.3(18.2-61.1)$ & & & Diverticulitis & $91(58.3)$ & $101(64.7)$ \\
\hline & & & & & & & Malignancy & $37(23.7)$ & \\
\hline & & & & & 1 & 29 (18.6) & $\begin{array}{l}\text { Perforation or } \\
\text { trauma }\end{array}$ & $13(8.3)$ & \\
\hline & & & & & 2 & $63(40.4)$ & Ischemia & $4(2.6)$ & \\
\hline & & & & & 3 & 54 (34.6) & Volvulus & $4(2.6)$ & \\
\hline & & & & & 4 & $10(6.4)$ & $\begin{array}{l}\text { Inflammatory } \\
\text { Bowel Disease }\end{array}$ & $2(1.3)$ & \\
\hline & & & & & & & $\begin{array}{l}\text { Anastomotic } \\
\text { leakage }\end{array}$ & $2(1.3)$ & \\
\hline & & & & & & & Other & $3(1.9)$ & \\
\hline
\end{tabular}


in $8.3 \%$, Clavien Dindo grade 3 occurred in $5.7 \%(n=9)$ and grade 4 in $2.6 \%(n=4)$ of the patients. Anastomotic leakage rate was 3.9\% $(n=6)$. Five of the patients with anastomotic leakage underwent reintervention under general anesthesia, two of them had their anastomosis disconnected into colostomies. The anastomosis of the other three patients could be salvaged by additional sutures at the staple line in one patient, additional stapling of the leaking rectal stump in one patient and drainage of the abscess and deviating ileostomy in one patient. One patient with anastomotic leakage presented with an intra-abdominal abscess which didn't require a re-intervention. Surgical site infection (SSI) was the most frequent complications and occurred in $14.7 \%(n=23)$. Six of the 23 patients with SSI developed this after conversion to open surgery, additional four of the 23 patients developed this after reoperation, these patients all had SSI of the laparotomy wound. The other 13 patients suffered from SSI of the old stoma incision. Overall median LOS was 4.0 days (range 1-69 days).

Four patients needed ICU admission, two were after anastomotic leakages, one patient with COPD suffered from a severe postoperative pneumonia and one patient needed rhythm observation due to severe tachycardia as a result of intra-abdominal abscess. None of these complications were deemed specific to the technique that was used, but are to be considered inherent to restoration of intestinal continuity procedures. Detailed overview of overall postoperative complications and complications per hospital can be found in Table 3.

\section{Operative technique}

Of the 156 procedures, two procedures (1.3\%) were not technically successful in restoring intestinal continuity, resulting in a surgical success rate of $98.7 \%$. Of the remaining 154 procedures, deviating stoma was needed in $2.6 \%$ of the procedures. SP approach was technically successful in $64.7 \%$ (101/156) of the procedures. Overall median operating time was 128 min (range 44-332). Conversion to multiport laparoscopy and open surgery was needed in $21.2 \%(n=33)$ and $12.8 \%(n=20)$, respectively. Additional ports were mostly needed for (extensive) adhesiolysis, oversewing the anastomosis after positive air leak testing or mobilizing the splenic flexure. Conversion to open surgery was significantly higher in patients who had an open index surgery compared to those who had a laparoscopic approach, 85.0\% (17/20) of the conversions occurred in patients with open index surgery $(p=0.03)$, albeit single-port and multiport laparoscopy was feasible in $80.2 \%$ (81/101) of the patients who underwent open index surgery. Overview of the overall surgical details and outcomes and per hospital can be found in Table 4 . Overview of the encountered intra-operative complications and reasons for conversion in ETH can be found in Online Appendix 1.

Table 3 30-day postoperative outcome

\begin{tabular}{|c|c|c|c|c|c|}
\hline 30-day postoperative outcome & $\begin{array}{l}\text { Humanitas } \\
\text { Italy }(n=13)\end{array}$ & $\begin{array}{l}\text { Churchill United } \\
\text { Kingdom }(n=30)\end{array}$ & $\begin{array}{l}\text { Zuyderland } \\
\text { Netherlands } \\
(n=9)\end{array}$ & $\begin{array}{l}\text { Elisabeth-TweeSteden } \\
\text { Netherlands }(n=104)\end{array}$ & Cumulative $(n=156)$ \\
\hline Median length of stay, days (range) & $6(3-19)$ & $5(2-35)$ & $3(1-11)$ & $4(1-69)$ & $4(1-69)$ \\
\hline Any postoperative complication, $n(\%)$ & $4(30.8)$ & $4(13.3)$ & $1(11.1)$ & $35(33.7)$ & $44(28.2)$ \\
\hline Anastomotic leakage, $n(\%)$ & $1(7.7)$ & - & $1(11.1)$ & $4(3.8)$ & $6(3.9)^{\mathrm{c}}$ \\
\hline Surgical site infection, $n(\%)$ & - & $1(3.3)$ & $1(11.1)$ & $21(20.2)$ & $23(14.7)$ \\
\hline Intra-abdominal abscess, $n(\%)$ & $1(7.7)$ & $2(6.7)$ & $1(11.1)$ & $4(3.8)$ & $8(5.1)$ \\
\hline Urogenital complication $^{\mathrm{a}}, n(\%)$ & - & $1(3.3)$ & - & $2(1.9)$ & $3(1.9)$ \\
\hline Postoperative ileus, $n(\%)$ & $1(7.7)$ & - & - & $5(4.8)$ & $6(3.9)$ \\
\hline Pulmonary complication, $n(\%)$ & - & $1(3.3)$ & - & $2(1.9)$ & $3(1.9)$ \\
\hline Bleeding-related complication $^{\mathrm{b}}, n(\%)$ & $1(7.7)$ & $2(6.7)$ & - & $2(1.9)$ & $5(3.2)$ \\
\hline \multicolumn{6}{|l|}{ Clavien-Dindo classification, $n(\%)$} \\
\hline I & $1(7.7)$ & - & - & $23(22.1)$ & $24(15.4)$ \\
\hline II & $1(7.7)$ & $2(6.7)$ & - & $4(3.8)$ & $7(4.5)$ \\
\hline III & $2(15.4)$ & $2(6.7)$ & $1(11.1)$ & $4(3.8)$ & $9(5.7)$ \\
\hline IV & - & - & - & $4(3.8)$ & $4(2.6)$ \\
\hline Mortality, $n(\%)$ & - & - & - & - & - \\
\hline
\end{tabular}

${ }^{\mathrm{a}}$ Urogenital complication: urine retention, urinary tract infection

${ }^{\mathrm{b}}$ Bleeding-related: rectal blood loss, haematoma in wound or anastomosis

${ }^{\mathrm{c}}$ Calculated over the number of patients who had successful reversal of left-sided colostomy, see Table 4 
Table 4 Surgical details and outcomes

\begin{tabular}{|c|c|c|c|c|c|}
\hline Surgical outcome & Humanitas Italy $(n=13)$ & $\begin{array}{l}\text { Churchill United } \\
\text { Kingdom }(n=30)\end{array}$ & $\begin{array}{l}\text { Zuyderland } \\
\text { Netherlands } \\
(n=9)\end{array}$ & $\begin{array}{l}\text { Elisabeth-TweeSteden } \\
\text { Netherlands }(n=104)\end{array}$ & Cumulative $(n=156)$ \\
\hline Surgical success rate, $n(\%)$ & $13(100)$ & $30(100)$ & $9(100)$ & $102(98.1)$ & $154(98.7)$ \\
\hline Deviating stoma, $n(\%)$ & - & $1(3.3)$ & $1(11.1)$ & $2(2.0)$ & $4(2.6)^{\mathrm{a}}$ \\
\hline Single-port success rate, $n(\%)$ & $13(100)$ & $12(40.0)$ & $9(100)$ & $67(65.7)$ & $101(64.7)$ \\
\hline Conversion & - & $18(60.0)$ & - & $35(34.3)$ & $53(34.0)$ \\
\hline Multiport laparoscopy & - & $12(40.0)$ & - & 21 & $33(21.2)$ \\
\hline Open & - & $6(20.0)$ & - & 14 & $20(12.8)$ \\
\hline Median operation time [range] & 160 [75-322] & $165[75-310]$ & $88[68-232]$ & 128 [40-332] & $128[40-332]$ \\
\hline
\end{tabular}

${ }^{a}$ Calculated over the number of patients who had successful reversal of left-sided colostomy

\section{Appraisal of the literature}

The specific details of the literature search in PubMed can be found in Online Appendix 2. The flow diagram of inclusion of the studies can be found in Fig. 1. A total of 86 studies were excluded for solely discussing laparoscopy $(n=15)$, comparing results of laparoscopic reversal versus open reversal of left-sided colostomy $(n=11)$, treatment of diverticulitis $(n=25)$, video vignettes $(n=4)$, using other novel techniques of stoma reversal $(n=5)$, case reports on stoma problems $(n=3)$ and other articles unrelated to singleport stoma reversal surgery $(n=23)$.

Three previous published articles on this topic from our current collaborative group of authors were excluded $[3,15$, 17], one article was excluded due to inclusion of their more recent manuscript [21], one meta-analysis on this topic was excluded since it had no additional new studies [22], leaving 5 included original articles [13, 14, 19, 23, 24].
Fig. 1 PRISMA flow diagram of included studies
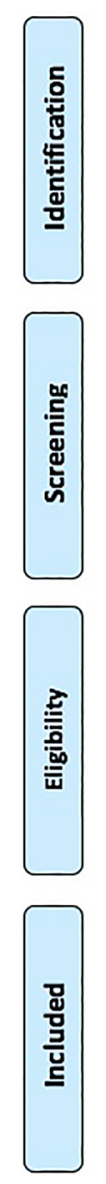

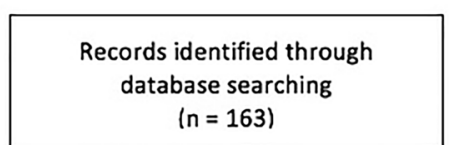
$(n=163$ )
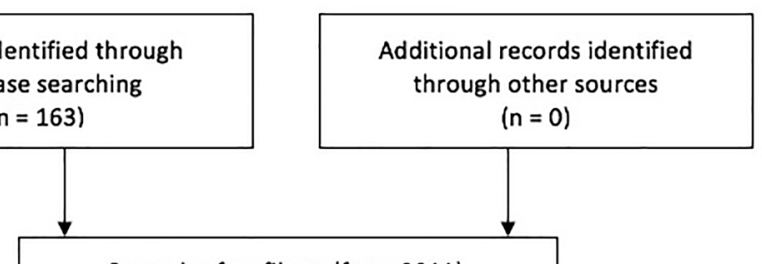

Records after filters (from 2011)

$$
(n=96)
$$
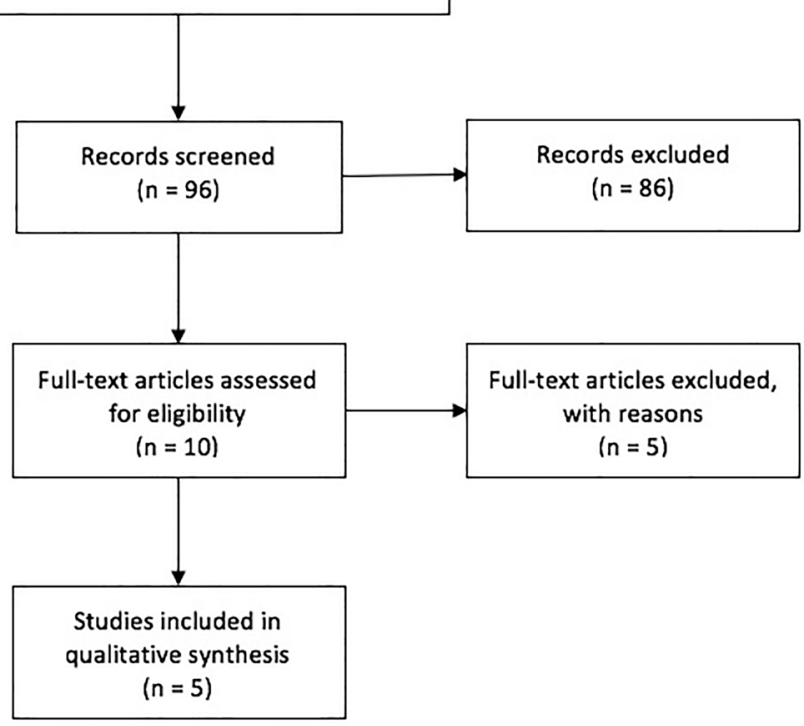

Studies included in $(n=5)$ 
This appraisal shows that since the introduction of the single-port approach in Hartmann's reversal in 2011 by Smith and Bettinger [13], additional case series have been published on this topic. At this moment no randomized controlled trials between the different approaches (open, laparoscopic or single-port) were published. Literature shows that patient selection for SPRLC is mainly in patients after laparoscopic index surgery $53.4 \%$ overall, figures ranging from 34 to $72.7 \%$. It also shows that SP approach is safe and feasible with high success rates, morbidity and mortality rates ranging from $12.5-30.4 \%$ and $1.8-2.2 \%$, respectively. Major complication rate is also low, varying from $0-8.9 \%$ and median LOS between $4-8$ days. Details and an overview can be found in Table 5 .

\section{Discussion}

The merits of the single-port reversal of left-sided colostomy compared to the open approach have been shown before [3, $11-15,17,19-21]$. The present series is, to our knowledge, the only and largest European multicenter cohort to date. This study shows that SPRLC is an attractive technique and with favorable postoperative outcomes across different hospitals in Europe. Acceptable rates of postoperative morbidity (28\%) and low rates of major complication (8\%) combined with a short postoperative hospitalization (median 3 to 6 days) after SPRLC could result in lowering a surgeons' threshold to restore intestinal continuity.

Our review and appraisal of the literature shows that type of single-port platform does not influence the favorable results after SPRLC. It appears that the postoperative results found in the literature are slightly better compared to the results found in our multicenter cohort. One reason might be that the majority of patients in this cohort have had open index surgery compared to the patients in the different cohorts in the literature (101/156 versus $61 / 131, p=0.003)$. Another reason might be a possible publication or selection bias of those smaller case series in the literature. It seems reasonable and sensible to perform a certain patient selection (ASA 1-2 patients with low BMI and swift uncomplicated recovery after a laparoscopic procedure) when one is still adapting to a new technique [14]. Our cohort, on the other hand, contains mostly ASA 2-3 patients with a tendency towards being overweight. As time progressed and sufficient exposure was gained, SPRLC evolved from a novel technique, to the preferred approach which was applied to all left-sided colostomy reversal surgeries in $\mathrm{ETH}, \mathrm{CH}$ and HRH. This might have resulted in an increase in conversions to multiport laparoscopy in the ETH cohort due to the inclusion of increasingly complex patients. Moreover, it needs to be stressed that the majority of these conversions consist of addition of one single $5 \mathrm{~mm}$ port, below the old laparotomy

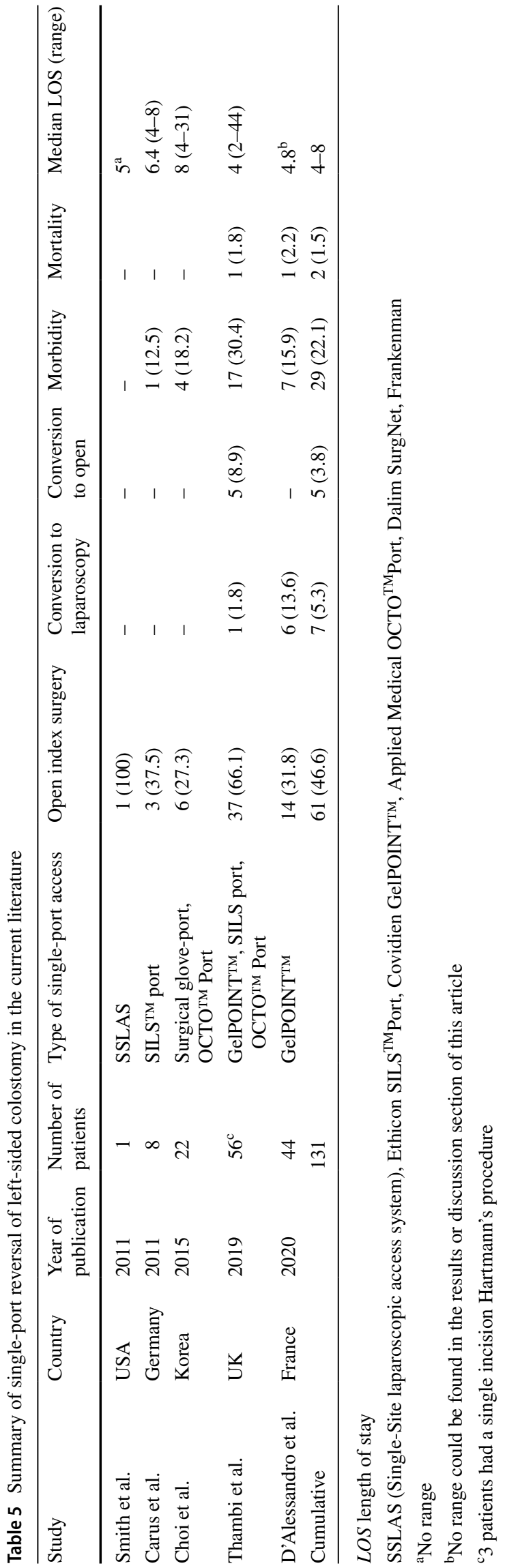


scar, not necessitating conversion to open laparotomy. Noteworthy is that $\mathrm{CH}$ cohort has an exceptionally high number of primary open approach in their mostly ASA 3 patients compared to others, which could be an explanation for their higher conversion rate during SPRLC.

Midline adhesiolysis or adhesiolysis in order to place trocars have become unnecessary when using the stoma fenestration as port, since the reversal of a left-sided colostomy takes place the left side of the abdomen alone. This advantage has been confirmed before [3, 13, 15, 23, 24]. Another advantage of SP is that it obviates the need to treat a concomitant complex abdominal wall defect or incisional hernia, this entire area can be left alone when using the stoma fenestration as access [15]. The use of a single-port with availability of multiple instruments through the stoma fenestration can be beneficial compared to conventional multiport laparoscopy, especially in patients after open surgery with extensive intra-abdominal adhesions. If needed, direct adhesiolysis can be safely performed first with those instruments through the single-port to ensure safe additional trocar placement elsewhere. This adhesiolysis to clear space for additional trocar placement is not always easy or feasible when using the conventional multiport laparoscopy.

SP surgery also has its down sides, it takes some adjustment from surgeons and surgical team to adapt to the offcentered vision and limited space to 'triangulate' the laparoscopic instruments. Despite this, we have shown before that experienced residents are able to perform this procedure under supervision, especially in centers with adequate experience and exposure in minimally invasive laparoscopic surgery [15].

This study is limited by the retrospective observational character; no randomization or case-matched comparisons have been carried out in this cohort. Another limitation of a retrospective observational study is the inability to include variables if they are not a part of the standard electronic patient records or operation reports, such as blood loss. Other factors such as enhanced recovery after surgery programs, low opioid anesthesia and analgesia or increasingly subspecialization of colorectal surgery with increasing laparoscopic index surgery could all have a part in the favorable results of SPRLC. Especially patient selection at surgeons' preference (such as in the ZMC cohort) might result in exceptionally favorable results. It would be an interesting avenue of further research to evaluate if a standardized way of using the a single-port in the stoma fenestration with adding one or two additional ports from the start of the procedure would result in better peri- and post-operative results with possibly increased uptake of this technique.

This study confirms the safety, feasibility and favorable results of the use of single-port approach in the reversal of left-sided colostomy in different centers in Europe with laparoscopic experienced colorectal surgeons. The available literature on this topic support and show equally favorable results using single-port laparoscopy for left-sided colostomy reversal surgery.

Supplementary Information The online version contains supplementary material available at https://doi.org/10.1007/s00464-021-08657-x.

Funding All the authors declare no sources of funding related to this manuscript.

\section{Declarations}

Disclosures Y. T. van Loon, S. H. E. M. Clermonts, E. H. J. Belgers, H. Kurihara, A. Spinelli, H. M. Joshi, K. J. Gorissen, D. D. E. Zimmerman have no conflicts of interest or financial ties to disclose.

Open Access This article is licensed under a Creative Commons Attribution 4.0 International License, which permits use, sharing, adaptation, distribution and reproduction in any medium or format, as long as you give appropriate credit to the original author(s) and the source, provide a link to the Creative Commons licence, and indicate if changes were made. The images or other third party material in this article are included in the article's Creative Commons licence, unless indicated otherwise in a credit line to the material. If material is not included in the article's Creative Commons licence and your intended use is not permitted by statutory regulation or exceeds the permitted use, you will need to obtain permission directly from the copyright holder. To view a copy of this licence, visit http://creativecommons.org/licenses/by/4.0/.

\section{References}

1. Vermeulen J, Gosselink MP, Busschbach JJ, Lange JF (2010) Avoiding or reversing Hartmann's procedure provides improved quality of life after perforated diverticulitis. J Gastrointest Surg 14(4):651-657

2. Leroy J, Cahill RA, Asakuma M, Dallemagne B, Marescaux J (2009) Single-access laparoscopic sigmoidectomy as definitive surgical management of prior diverticulitis in a human patient. Arch Surg 144(2):173-179 (discussion 9)

3. Clermonts SH, de Ruijter WM, van Loon YT, Wasowicz DK, Heisterkamp J, Maring JK et al (2016) Reversal of Hartmann's procedure utilizing single-port laparoscopy: an attractive alternative to laparotomy. Surg Endosc 30(5):1894-1901

4. van Hooft JE, Bemelman WA, Oldenburg B, Marinelli AW, Lutke Holzik MF, Grubben MJ et al (2011) Colonic stenting versus emergency surgery for acute left-sided malignant colonic obstruction: a multicentre randomised trial. Lancet Oncol 12(4):344-352

5. Arezzo A, Passera R, Lo Secco G, Verra M, Bonino MA, Targarona $\mathrm{E}$ et al (2017) Stent as bridge to surgery for left-sided malignant colonic obstruction reduces adverse events and stoma rate compared with emergency surgery: results of a systematic review and meta-analysis of randomized controlled trials. Gastrointest Endosc 86(3):416-426

6. Verweij NM, Hamaker ME, Zimmerman DD, van Loon YT, van den Bos F, Pronk A et al (2017) The impact of an ostomy on older colorectal cancer patients: a cross-sectional survey. Int J Colorectal Dis 32(1):89-94

7. Pearce NW, Scott SD, Karran SJ (1992) Timing and method of reversal of Hartmann's procedure. Br J Surg 79(8):839-841 
8. Wigmore SJ, Duthie GS, Young IE, Spalding EM, Rainey JB (1995) Restoration of intestinal continuity following Hartmann's procedure: the Lothian experience 1987-1992. Br J Surg 82(1):27-30

9. Albarran SA, Simoens C, Van De Winkel N, da Costa PM, Thill V (2009) Restoration of digestive continuity after Hartmann's procedure: ASA score is a predictive factor for risk of postoperative complications. Acta Chir Belg 109(6):714-719

10. Banerjee S, Leather AJ, Rennie JA, Samano N, Gonzalez JG, Papagrigoriadis S (2005) Feasibility and morbidity of reversal of Hartmann's. Colorectal Dis 7(5):454-459

11. Toro A, Ardiri A, Mannino M, Politi A, Di Stefano A, Aftab Z et al (2014) Laparoscopic reversal of Hartmann's procedure: state of the art 20 years after the first reported case. Gastroenterol Res Pract 2014:530140

12. Lucchetta A, De Manzini N (2016) Laparoscopic reversal of Hartmann procedure: is it safe and feasible? Updates Surg 68(1):105-110

13. Smith BM, Bettinger DA (2011) Single-incision laparoscopic reversal of Hartmann procedure via the colostomy site only: first report. Surg Innov 18(4):NP5-7

14. Choi BJ, Jeong WJ, Kim YK, Kim SJ, Lee SC (2015) Single-port laparoscopic reversal of Hartmann's procedure via the colostomy site. Int J Surg 14:33-37

15. van Loon YT, Clermonts SHEM, Wasowicz DK, Zimmerman DDE (2020) Reversal of left-sided colostomy utilizing single-port laparoscopy: single-center consolidation of a new technique. Surg Endosc 34(1):332-338

16. University of Bern (2014) STROBE statement (STrenghthening the Reporting of OBservational studies in Epidemiology). https:// www.strobe-statement.org/index.php?id=strobe-home

17. Joshi HM, Gosselink MP, Adusumilli S, Cunningham C, Lindsey I, Jones OM (2014) Incision-less reversal of Hartmann's procedure. Tech Coloproctol 18(9):843-846
18. de Nes LCF, Bacchelli C, Montorsi M, Spinelli A (2016) Singleport laparoscopic Hartmann reversal through the stoma site-a video vignette. Colorectal Dis 18:215-215

19. Carus T, Emmert A (2011) Single-port laparoscopic reversal of Hartmann's procedure: technique and results. Minim Invasive Surg 2011:356784

20. Gustafsson UO, Scott MJ, Schwenk W, Demartines N, Roulin D, Francis N et al (2013) Guidelines for perioperative care in elective colonic surgery: Enhanced Recovery After Surgery (ERAS((R))) Society recommendations. World J Surg 37(2):259-284

21. Kanalaka V, Borowski DW, Agarwal AK, Tabaqchali MA, Garg DK, Gill TS (2012) Comparative study of safety and outcomes of single-port access versus conventional laparoscopic colorectal surgery. Tech Coloproctol 16:423-428

22. Guerra F, Coletta D, Del Basso C, Giuliani G, Patriti A (2019) Conventional versus minimally invasive Hartmann takedown: a meta-analysis of the literature. World J Surg 43:1820-1828

23. Thambi P, Borowski DW, Sathasivam R, Obuobi RB, Viswanath YKS, Gill TS (2019) Single-incision laparoscopic reversal of Hartmann's operation through the stoma site: comparative outcomes with conventional laparoscopic and open surgery. Colorectal Dis 21(7):833-840

24. D'Alessandro A, Gumbs AA, Cartillone M, Elkary N, Chahine E, Chouillard E (2020) Trans-stomal single-port laparoscopic Hartmann's reversal is an efficacious and efficient procedure: a case-controlled study. Tech Coloproctol 24(5):455-462

Publisher's Note Springer Nature remains neutral with regard to jurisdictional claims in published maps and institutional affiliations. 